\title{
Aspects regarding operation characteristics of brushless direct current motors
}

\author{
Ion Vlad, Sorin Enache, Monica Adela Enache \\ University of Craiova, Faculty of Electrical Engineering, Craiova, Romania
}

\section{Email address:}

ivlad@em.ucv.ro (I. Vlad), senache@em.ucv.ro (S. Enache), menache@em.ucv.ro (M. A. Enache)

\section{To cite this article:}

Ion Vlad, Sorin Enache, Monica Adela Enache. Aspects Regarding Operation Characteristics of Brush-less Direct Current Motors. Journal of Electrical and Electronic Engineering. Vol. 2, No. 2, 2014, pp. 41-46. doi: 10.11648/j.jeee.20140202.12

\begin{abstract}
The researches regarding optimization in the area of electrical machines, include with priority the problem of the energy efficiency, by increasing the efficiency and the power factor. The objectives followed in this paper are the analysis of the operation characteristics, the fabrication and exploitation cost for brushless direct current motors rated at very low power. The utilization of permanent magnets having high specific energy in the construction of these motors influenced the machine performances, the cost and exploitation price. The research carried out aims at reducing the electrical energy consumption in exploitation by optimally dimensioning the permanent magnets. The last part of the paper compares two motors (brushless direct current motor and synchronous motor), both of them having permanent magnets, the same rated data, the same electromagnetic stresses and the same main constructive dimensions. It results that, using the brushless direct current motor instead of the synchronous one, the consumption of active electrical energy is reduced with $11.8 \%$, and the machine weight is reduced with $12.7 \%$.
\end{abstract}

Keywords: Brushless Direct Current Motors, Modelling, Simulation, Characteristics

\section{Introduction}

Further on there is presented an analysis carried out for a brushless direct current motor, regarding its design, technical and economic parameter and its operation characteristics.

The judicious choice of the type of electrical motor has a strong influence upon the gauge and the weight of the equipment, by the command scheme and the dynamic features of the drive.

Brushless direct current motors are widely used for electrical drive systems [2]-[4]. Among their benefits, we can mention high efficiency, stable and reliable operation [7], [9], [25]..

The analysis presented further on is useful to maximize the useful magnetic flux, which might lead to an efficient utilization of the active materials of the motor [12].

The present technique is conditioned by the utilization of permanent magnets [3], [5]-[6], [11], [13], which are present in the construction of several equipments. The most numerous applications are in the area of energy conversion, the permanent magnets being widely used in the construction of electrical machines.

The development of the fabrication technology for rare earths based permanent magnets has led to the increase of the production and to the decrease of their cost price.

Their utilization in excitation systems has made possible to obtain some motors having a very high ratio torque developed/unit of volume, better performances, by miniaturization, some compact and reliable equipments. The lack of the excitation winding makes brushless direct current motors to have a better efficiency and a lower volume in comparison with the classical ones [18]-[19], [24]. For a certain air-gap magnetic induction, the volume of an inductor having permanent magnets is smaller than in the case of an inductor having electromagnetic inductor.

In this study [16]-[17], we have approached the permanent magnet direct current motors rated at very low power, used for DVD, tape recorders, office equipments, portable devices for sound recording and reproduction etc.

For design and exploitation it is necessary to know some exact mathematical models, in order to obtain good performances in operation. On the basis of the analytical model, by numerical modeling [1], [8], [10], the design has been conceived then the characteristics required in exploitation have been computed and plotted.

In these circumstances, the theme approached in this research is a subject of large interest for engineering area. 


\section{Aspects Regarding Design of Brushless Direct Current Motors}

\subsection{Mathematical Model of the Motor}

The electromagnetic stresses and the main constructive dimensions have an important role in the design of brushless direct current motors 6], [9], [17], with major effects upon the operation characteristics and the exploitation cost. For the direct current motor analyzed here, the stator is the mobile part and it has permanent magnets and the command winding is placed on the rotor, which is the fix part of the machine.

The computation of the magnetic field is the basic problem when studying electrical machines; solving it adequately, it is possible to carry out a correct analysis of the operation regimes (steady state, dynamic regime etc.), a judicious design, based on coefficients - correctly determined - so it is possible to obtain some machines having maximal overall technical and economic parameters.

The computation of the magnetic field uses Kirchhoff's theorems for magnetic circuits, using the equivalent scheme by evaluating the magnetic reluctances of the circuit parts and of the ampere-turns applied.

\subsection{Criterion Analyzed and Objective Function}

The mathematical model used to design the motor, to establish the operation characteristics, to determine the costs (fabrication, exploitation and total) is known in the literature [12], [14], [20]-[22].

The research carried out shows how the energy consumption can be reduced in exploitation [18], [20], by choosing adequately the permanent magnet. That is why, there has been chosen the criterion $\mathrm{C}_{\mathrm{e}}$-exploitation cost and the objective function has resulted:

$$
f(\bar{x})=C_{e}=N_{o u} T_{r i} c_{e l . a} \Sigma p
$$

where: $\mathrm{N}_{\mathrm{ou}}$-annual number of operation hours; $\mathrm{c}_{\mathrm{el} . \mathrm{a}}-$ costs of a $\mathrm{kWh}$ of active electrical energy, $\mathrm{T}_{\mathrm{ri}}$-time of investment recovery; $\Sigma \mathrm{p}$-total losses of active power for rated load operation.

\section{Results, Simulations and Conclusions}

In order to present concrete data regarding the performances of the brushless direct current motor, there has been considered a machine rated as follows: $\mathrm{P}_{\mathrm{N}}=5 \mathrm{~W}$-rated power, $\mathrm{U}_{\mathrm{N}}=12 \mathrm{~V}$-rated voltage, $\mathrm{n}_{\mathrm{N}}=3000$ r.p.m. -rated speed. The electromagnetic stresses are: $A_{m}=40 \mathrm{~A} / \mathrm{cm}$ -current load, $\mathrm{B}_{\mathrm{m}}=0.3 \mathrm{~T}$-air-gap magnetic induction, $\mathrm{J}_{\mathrm{a} . \mathrm{m}}=2.5 \mathrm{~A} / \mathrm{mm}^{2}$-current density of the winding, $\mathrm{B}_{\mathrm{dm}}=1.6 \mathrm{~T}$ -tooth magnetic induction, $\mathrm{B}_{\mathrm{jam}}=1.46 \mathrm{~T}$-yoke magnetic induction and the main constructive dimensions: $\mathrm{D}_{\mathrm{m}}=40 \mathrm{~mm}$ -machine diameter, $\delta_{\mathrm{m}}=0.3 \mathrm{~mm}$-air-gap. The gauge dimensions of the machine are: $\mathrm{D}_{\mathrm{em}}=58 \mathrm{~mm}$-outer diameter, $\mathrm{L}_{\mathrm{em}}=47 \mathrm{~mm}$-total length.
The costs of fabrication and exploitation have been computed on the basis of the existing documentation: $\mathrm{N}_{\text {ore }}=250 * 8=2000$ hours/year -annual number of operation hours; $\mathrm{T}_{\mathrm{ri}}=4$ years -time of investment recovery; $\mathrm{c}_{\mathrm{Cu}}=12$ $\mathrm{E} / \mathrm{kg}-$ cost of a kilo of copper, $\mathrm{c}_{\mathrm{Fe}}=0.95 \mathrm{E} / \mathrm{kg}-$ cost of a kilo of electrotechnical steel, $c_{\text {el. }}=0.132 \mathrm{E} / \mathrm{kWh}-$ cost of a $\mathrm{kWh}$ of active electrical energy.

It is necessary to have a high value of the inertia moment, because the motor must not be sensitive to load shocks. That is why, there will be adopted the solution with exterior inductor (rotor), made by a ring-shaped magnet and with interior induced armature (stator). In the construction of the brushless direct current motor analyzed there have been used permanent magnets belonging to the fourth class, the rare-earths based permanent magnets (having in their composition expensive materials - cobalt and samarium rare materials all over the world), which have very high middle remanent magnetic inductions, intensities of coercive magnetic fields and maximum magnetic energies. The operation point of the magnet will be on the demagnetization characteristic, its position being given by the configuration of magnetic circuit in which the magnet is placed. It is noticed that when the magnetic field intensity increases, the flux provided by the magnet decreases.

\subsection{Magnet Dimensioning and Operation Point Establishing}

Further on there are presented a few important details regarding the magnet dimensioning. In the figure 1 there are presented the curves used [15], [17] and the way to determine the operation point on the return line for the permanent magnet direct current motor stabilized in air (the motor was disassembled at least once).

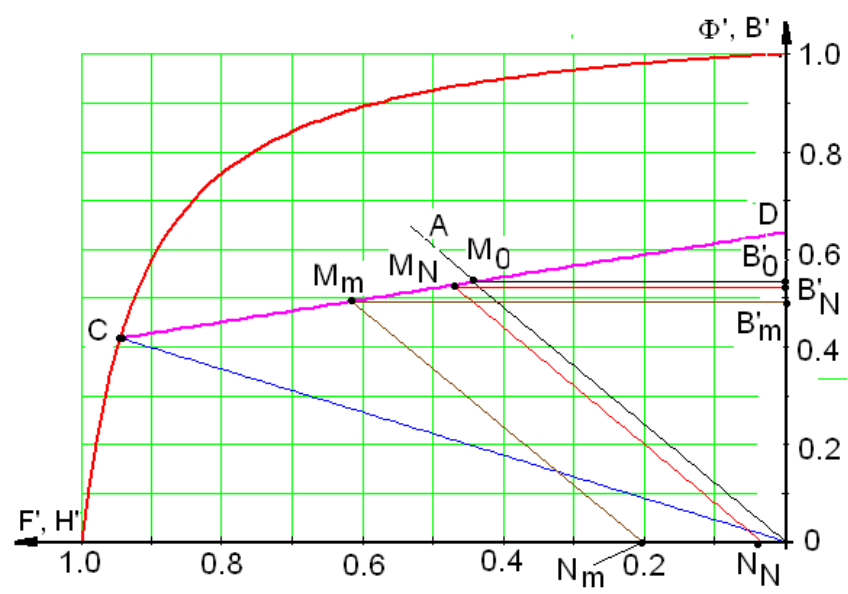

Figure 1. Determination of the operation point on the return line of the permanent magnet.

The stages are as follows:

- for the permanent magnet used, the demagnetization curve is plotted in per unit, $\Phi^{\prime}=\mathrm{f}\left(\mathrm{F}^{\prime}\right)$, being computed as: 


$$
B_{s}^{\prime}=B_{s}^{\prime} \frac{1-H_{s}^{\prime}}{B_{s}^{\prime}-H_{s}^{\prime}}
$$

where $\mathrm{B}_{\mathrm{s}}$ and $\mathrm{H}_{\mathrm{s}}$ are the per unit values of the saturation induction and of the magnetic field intensity.

-the line OA is plotted; it is the dependence of the per unit exterior magnetic flux of the magnet upon the per unit electromotive force, which form an angle with $\mathrm{Ox}$ :

$$
\alpha_{1}=\operatorname{arctg} \Lambda^{\prime}
$$

-the line $\mathrm{OC}$ is the dependence of the free magnetic flux upon the per unit magnetomotive force, having an angle with Ox:

$$
\alpha_{2}=\operatorname{arctg} \Lambda_{1}^{\prime}
$$

-the return line $\mathrm{CD}$ is plotted, having an angle to the horizontal line:

$$
\mu_{n}=\operatorname{arctg} \mu_{r e v}^{\prime}
$$

-on the Ox axis there are fixed the points $\mathrm{N}_{\mathrm{m}}$ and $\mathrm{N}_{\mathrm{N}}$ taking the following relation into account:

$$
O N_{m}=F_{a d . \max }^{\prime} \quad O N_{N}=F_{a d . N}^{\prime}
$$

-the lines $\mathrm{N}_{\mathrm{m}} \mathrm{M}_{\mathrm{m}}$ and $\mathrm{N}_{\mathrm{N}} \mathrm{M}_{\mathrm{N}}$ are plotted parallel to $\mathrm{OA}$; -the ordinates of the points $\mathrm{M}_{\mathrm{m}}, \mathrm{M}_{\mathrm{N}}$ and $\mathrm{M}_{0}$ are the per unit values $\mathrm{B}^{\prime}{ }_{\mathrm{M} 0}, \mathrm{~B}^{\prime}{ }_{\mathrm{MN}}$ and $\mathrm{B}^{\prime}{ }_{\mathrm{Mm}}$ for the magnetic inductions at no-load operation, load operation and the maximum possible load operation;

-there are computed total flux of the magnet $\Phi_{\mathrm{mg}}$ :

$$
\Phi_{m g}=B_{M_{N}}^{\prime} B_{r} S_{m g}
$$

and the air-gap useful flux $\Phi$ of the motor

$$
\Phi=\frac{\Phi_{m g}}{k_{\sigma i}}
$$

The notations used are: $\Lambda^{\prime}$-per unit magnetic permeance of the magnetic circuit, $\Lambda^{\prime}{ }_{1}$-per unit leakage permeance of the free magnet, $\mu_{\text {rev }}^{\prime}$-per unit value of the reversible permeability, $F_{\text {ad.max }}$-maximum per unit value of the longitudinal armature reaction, $F_{\text {ad.N }}$-per unit value of the longitudinal armature reaction at rated load, $\mathrm{B}_{\mathrm{r}}$-remanent induction, $\mathrm{S}_{\mathrm{mg}}$-surface of the magnet, $\mathrm{k}_{\sigma \mathrm{i}}$-leakage coefficient of the inductor.

Finally it is imposed to have a maximum difference of $5 \%$ between $\Phi$, computed this way and the value from the project. If not, the dimensions of the magnet ate modified and then the stages presented before are resumed.

All these operations are performed by a specialized sub-program, afferent to the main design program. This way the computation time is much reduced, an optimal design may be approached and the results obtained have small errors.

\subsection{Analysis of Operation Characteristics}

Further on there are presented the operation characteristics of the brushless direct current motor designed, analyzed as concern the performances. In order to carry out an efficient analysis there are presented the important characteristics of the motor; they are plotted in separate graphics: $\mathrm{I}=\mathrm{f}\left(\mathrm{P}_{2}\right)$, current curve (Fig.2), $\mathrm{P}_{1}=\mathrm{f}\left(\mathrm{P}_{2}\right)$ curve of the power received from the source (Fig.3), $\mathrm{M}=\mathrm{f}\left(\mathrm{P}_{2}\right)$ curve of the electromagnetic torque (Fig.4), $\mathrm{n}=\mathrm{f}\left(\mathrm{P}_{2}\right)$ speed curve (Fig.5), $\eta=f\left(P_{2}\right)$ efficiency curve (Fig.6). Since the winding inductance may be neglected in comparison with its resistance, the mechanic characteristic becomes practically linear (Fig.5). In case of low and very low powers, the comparison with the classical direct current motor is favourable because the losses caused by the brushes friction on the commutator and the electrical losses in the sliding contact do not occur; thus a better efficiency results (Fig.6).

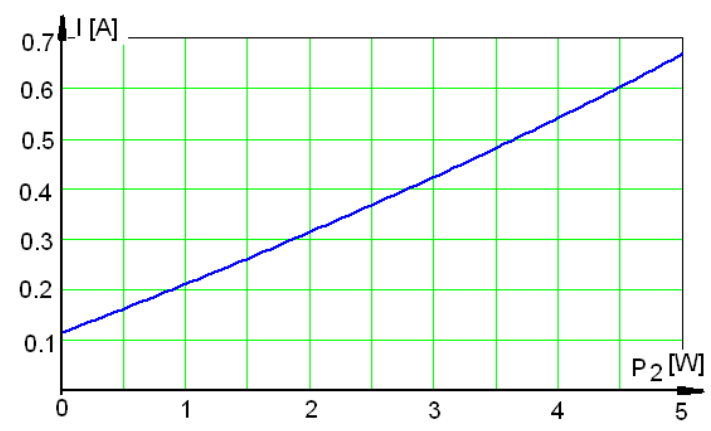

Figure 2. Current characteristic relatively to the useful power.

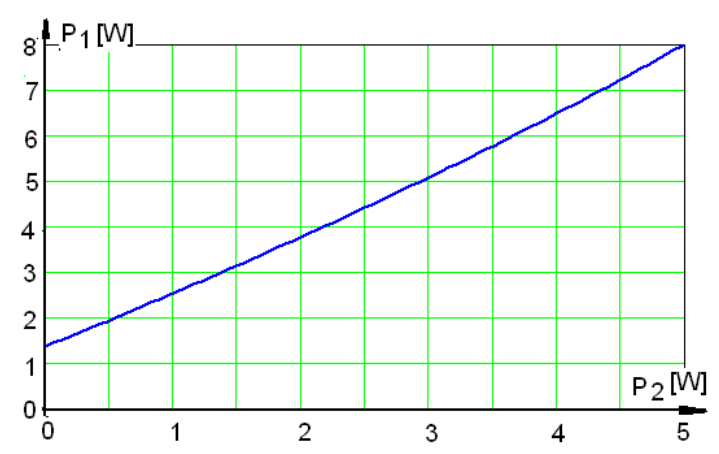

Figure 3. Power characteristic received from the source relatively to the useful power.

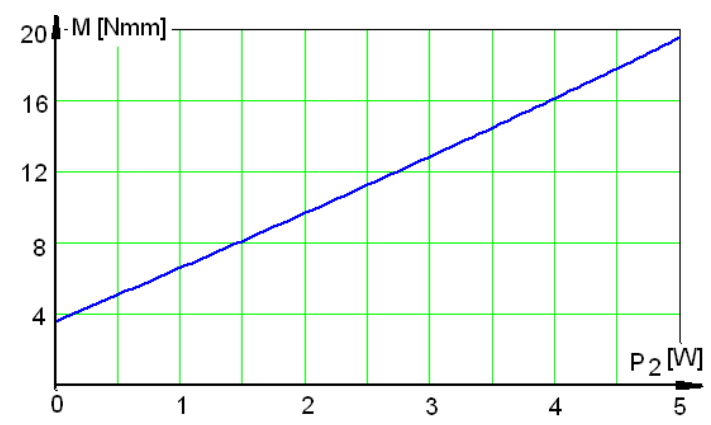

Figure 4. Electromagnetic torque characteristic relatively to the useful power. 


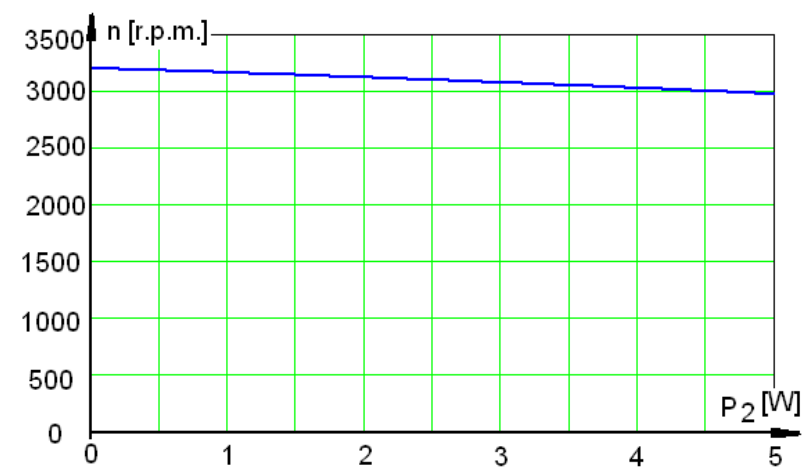

Figure 5. Speed characteristic relatively to the useful power.

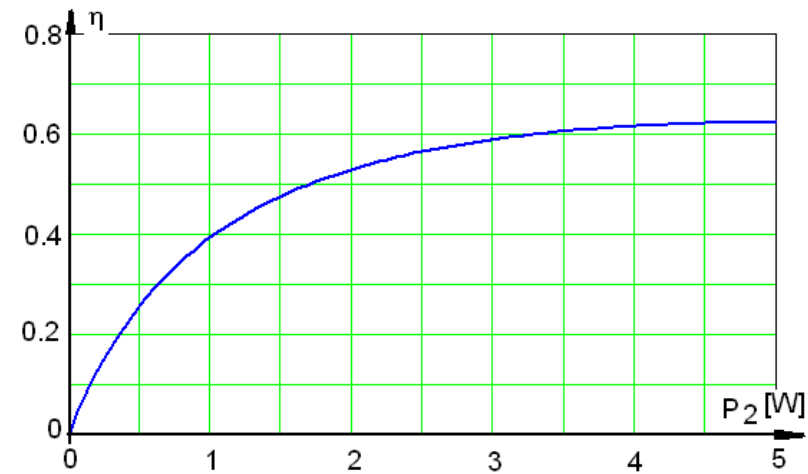

Figure 6. Efficiency characteristic relatively to the useful power.

We notice the same shape of the characteristics as in the case of shunt direct current motor, a good efficiency, almost constant inside the operation range.

The efficiency curve has been plotted considering the losses in the command source. The motor is optimally dimensioned, because at rated load there is accomplished the condition $\mathrm{p}_{\mathrm{Cu}}=\mathrm{p}_{\mathrm{Fr}}+\mathrm{p}_{\mathrm{Fe}}$ (constant losses equal to variable losses). In Fig.7 there are presented the curves for the main losses of the motor, relatively to $\Sigma_{\mathrm{pN}}$-rated losses, when the load is modified in normal limits. The notations are: $\Sigma p$ -total losses, $\mathrm{p}_{\mathrm{fr}}$-friction losses, $\mathrm{p}_{\mathrm{Cu}}-$ winding losses, $\mathrm{p}_{\mathrm{Fe}}$ -iron losses, $\mathrm{p}_{\mathrm{c}}-$ command circuit losses.

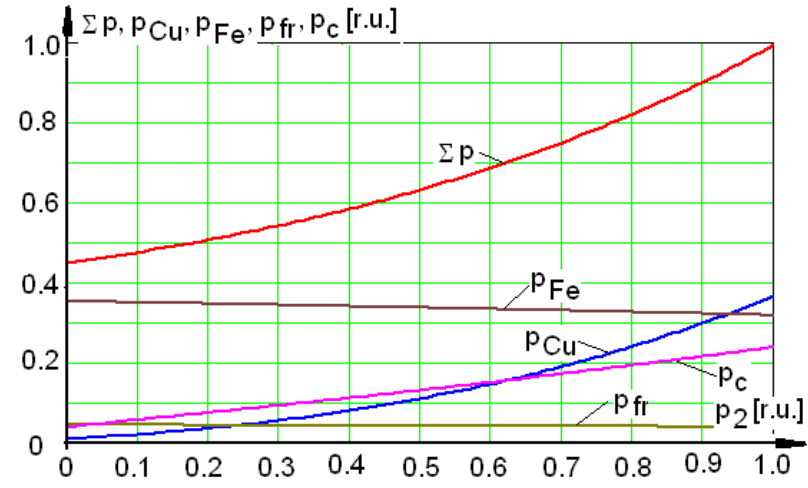

Figure 7. Motor losses relatively to the total losses at rated load operation.

The same characteristics, but in per unit, are all plotted in the same graphic (Fig.8 and Fig.9). The notations are: $p_{1}$ -power received (red colour), $\mathrm{i}$-current (dotted blue line), $\mathrm{n}$ -speed (green colour), $\mathrm{m}$-electromagnetic torque (light green colour), $\mathrm{m}_{2}$-useful mechanic torque (brown colour), $\eta$ -efficiency (pink colour).

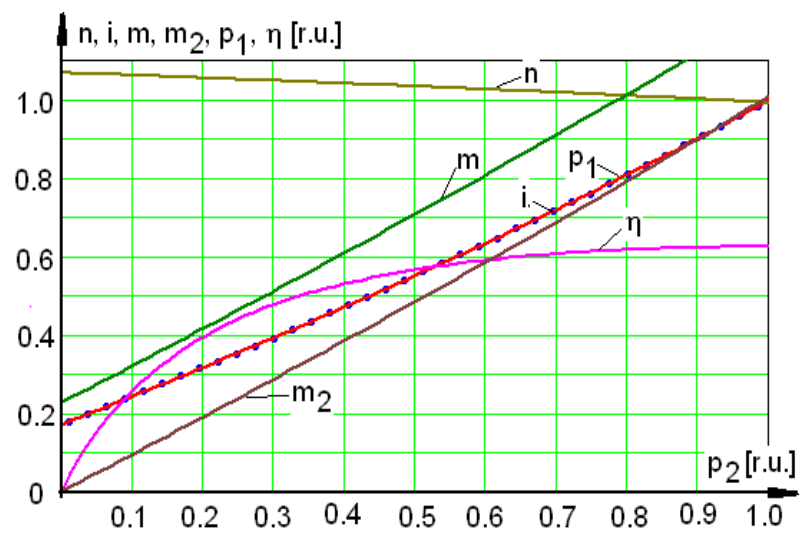

Figure 8. Operation characteristics in per unit, normal load.

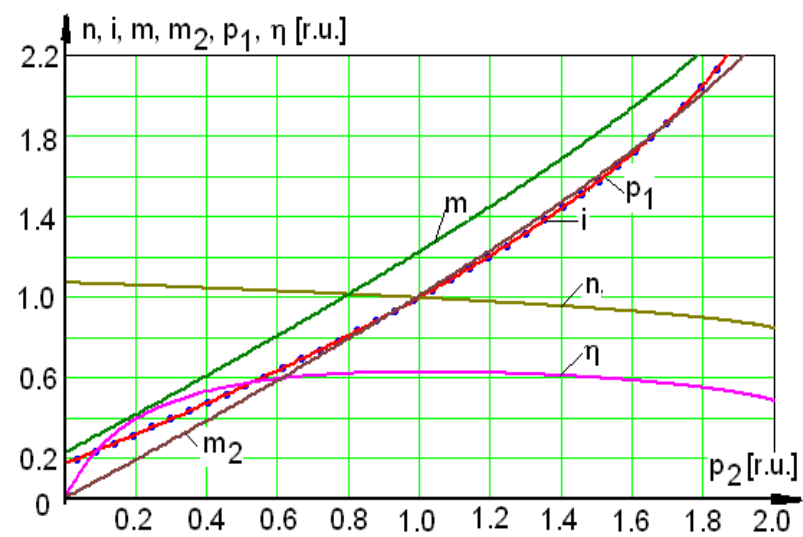

b)

Figure 9. Operation characteristics in per unit, short time over-load.

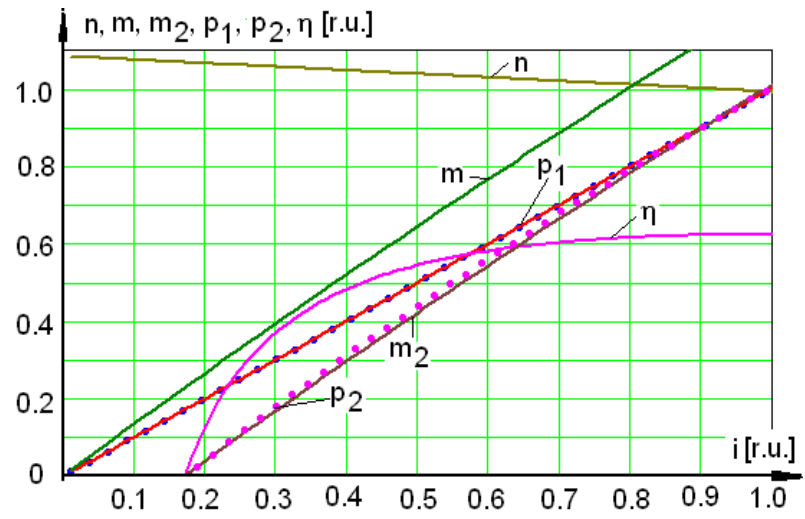

Figure 10. Operation characteristics in per unit relatively to the current.

In figure 8 we have plotted the operation characteristics of the brushless direct current motor analyzed, when the load is between normal limits. For a short time accidental over-load $\left(\mathrm{P}=0 \div 2 * \mathrm{P}_{\mathrm{N}}\right)$, the same characteristics are plotted in figure 9 . For certain analyses it is recommended to plot these characteristics relatively to the variable $i$-current (Fig.10).

The alternating current motors rated at low powers are inferior to brushless direct current motors, which have 
possibilities of smooth adjustment in a large range of speed and they also has high starting torque. The absence of the commutator and its replacement by a static commutator make this motor competitive with alternating current motors by the constructive simplicity, operation reliability, very low noise, high efficiency and high speed.

\subsection{Technical and Economic Aspects}

In order to emphasize the benefits of brushless direct current motor, this is compared to a permanent magnet synchronous motor, which has been designed at the same rated data, electromagnetic stresses and main dimensions. The design has been carried out according to knowledge from the literature and the results obtained for the two types of motors are filled in table 1 .

\section{Table 1}

\begin{tabular}{lcl}
\hline $\begin{array}{l}\text { Rated data/ } \\
\text { Characteristics }\end{array}$ & $\begin{array}{l}\text { Brushless direct } \\
\text { current motor }\end{array}$ & $\begin{array}{l}\text { Permanent magnet } \\
\text { synchronous motor }\end{array}$ \\
\hline $\mathrm{P}_{\mathrm{N}}[\mathrm{kW}]$-rated power & 5.0 & 5.0 \\
$\mathrm{U}_{\mathrm{N}}[\mathrm{V}]-$ rated voltage & 12 & 12 \\
$\mathrm{n}_{\mathrm{N}}[\mathrm{r} . \mathrm{p} . \mathrm{m}$.$] -rated speed$ & 3000 & 3000 \\
Machines designed according to the literature & \\
$\mathrm{I}_{\mathrm{N}}[\mathrm{A}]$-rated current & 0.67 & 0.739 \\
$\mathrm{M}_{\mathrm{N}}[\mathrm{Nmm}]$-rated torque & 16 & 16 \\
$\mathrm{P}_{1 \mathrm{~N}}[\mathrm{~kW}]$-active power & 8.035 & 10.03 \\
$\mathrm{Q}_{1 \mathrm{~N}}[\mathrm{kVA}]$-reactive power & 0 & 12.01 \\
$\Sigma_{\mathrm{p}}[\mathrm{kW}]$-total losses & 3.035 & 4.033 \\
$\eta$-efficiency & 0.622 & 0.556 \\
$\mathrm{De}[\mathrm{mm}]$-outer diameter & 67.3 & 71.7 \\
$\mathrm{Le}[\mathrm{mm}]$ - total length & 45.1 & 48.2 \\
$\mathrm{~m}[\mathrm{~kg}]-$ motor weight & 0.39 & 0.44 \\
$\mathrm{C}_{\mathrm{t}}[\mathrm{E}]-$ total cost & 13.99 & 16.97 \\
$\mathrm{C}_{\mathrm{f}}[\mathrm{E}]-$ fabrication cost & 6.78 & 8.55 \\
$\mathrm{C}_{\mathrm{e}}[\mathrm{E}]$ - exploitation cost & 7.21 & 8.42 \\
\hline
\end{tabular}

Direct current motors with static commutation have a fast response to commands and a wide range of speed adjustment (the maximum speed is only limited by the bearing type and by the centrifugal force).

For the motor analyzed, using a specialized program conceived by authors, it is possible to carry out the scale draw of the motor (longitudinal and cross sections Fig.11). This way we can have an overview and constructive details for doing corrections if necessary.
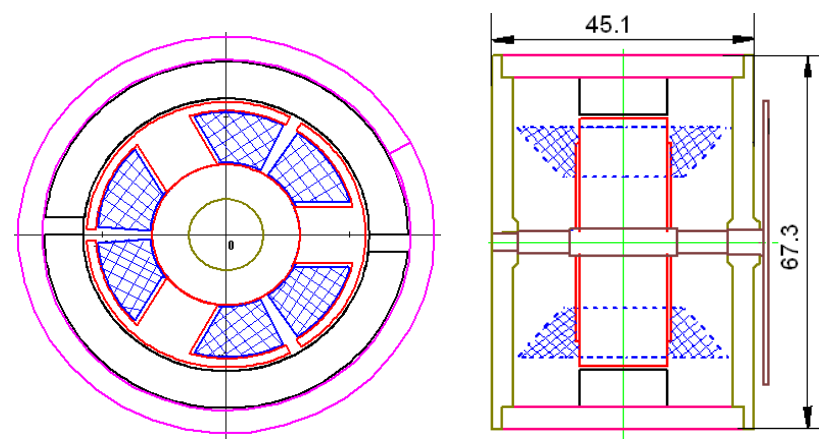

Figure 11. Cross section and longitudinal section through the motor analyzed.

\section{Conclusions}

The last part of the study has presented two motors (direct current and synchronous), both of them with permanent magnet, the same rated data, the same electromagnetic stresses and main constructive dimensions. As a consequence, the two motors are built under identical conditions, and we may analyze, by comparison, the load operation characteristics, the exploitation energy consumption etc.

This comparison allows us to establish that the brushless direct current motor is better for low power. Considering that the problem to reduce the energy consumption for equipments driven by low power motors is a very present one, the study carried out takes this aspect into account.

The utilization of the brushless direct current motor which has a better efficiency and does not use reactive power, instead of the permanent magnet synchronous motor, means a decrease of the active electrical energy consumption with $11.8 \%$, a decrease of the weight with $12.7 \%$ and a decrease of the total cost with $21.3 \%$.

The utilization of the synchronous motor needs a voltage and frequency static converter, which complicates the scheme, decreases the technical and economic parameters (larger gauge, lower overall efficiency, increases the weight and the cost of the motor etc).

\section{Acknowledgment}

This work was partially supported by the grant number P09004/1137/31.03.2014, cod SMIS 50140, entitled: Industrial research and experimental development vehicles driven by brushless electrical motors supplied by lithium-ion accumulators for people transport - GENTLE ELECTRIC.

\section{References}

[1] Ancau M., Nistor I.: Tehnici numerice de optimizare în proiectarea asistatá de calculator. Bucuresti, Ed. Tehnicá, 1996.

[2] Abbaszadeh K., Rezaee Alam F., Teshnehlab M.: Slot opening optimization of surface mounted permanent magnet motor for cogging torque reduction, Energy Conversion and Management 55, 2012, pp.108-115.

[3] Aydin M.: Magnet Skew in Cogging Torque Minimization of Axial Gap Permanent Magnet Motors, Proceedings of the 2008 International Conference on Electrical Machines, 2008.

[4] Biro K., Viorel I.A., Szabo L., Henneberger G.: Special electrical machines, MEDIAMIRA Press, Cluj-Napoca, 2005.

[5] Bianchini C., Immovilli F., Lorenzani E., Bellini A., Davoli M.: Review of Design Solutions for Internal Permanent Magnet Machines Cogging Torque Reduction, 2011, Ieee Transactions on Magnetics, vol. 48, no.10, 2012, pp.2685-2693. 
[6] Boatman A.: Switching Circuit for a Permanent Magnet DC Motor, Senior Project Electrical Engineering Department California Polytechnic State University San Luis Obispo, 2009.

[7] Brunner C.U.: International Standar/ds for Electric Motors, Standards for En.Efficiency of Electric Motor Systems (SEEEM), 2007, pp. 6-10.

[8] Campeanu A., Vlad I., Enache S.: Numerical Analysis of the Dynamic Behavior of a High Power Salient Pole Synchronous Machine by using a Corrected Model, AECE Journal, Vol.12, Issue 1, Year 2012, ISSN: 1582-7445, e-ISSN: 1844-7600, pp.97-102.

[9] Centner M., Schäfer U.: Machine design software for induction machines, in Proc. ICEM, Vilamoura, Portugal, 2008, pp. 1-4.

[10] Daniel I., Munteanu I., s.a.: Metode numerice in ingineria electrica. Bucuresti, Editura Matrix Rom, 1998.

[11] EL-Refaie A.: Fractional-Slot Concentrated-Windings Synchronous Permanent Magnet Machines: Opportunities and Challenges, Ieee Trans. on Industrial Electronics, vol. 57, no. $1,2010$.

[12] Faiz J., Sharifian M.B.B.: Optimal design of three-phase Induction Motors and their comparison with a typical industrial motor, Computers and Electrical Engineering, vol. 27, 2001, pp. 133-144.

[13] Guemes J.A., Iraolagoitia A.M., Del Hoyo J.I., Fernandez P.: Torque Analysis in Permanent-Magnet Synchronous Motors: A Comparative Study, Ieee Trans on Energy Conversion, vol. 26, no. 1, 2011.

[14] Liuzzi G., Lucidi S., Parasiliti F., Villani M.: Multiobjective optimization techniques for the design of induction motors, IEEE Trans. on Magnetics, vol. 39, no. 3, May 2003.

[15] Magureanu R., Vasile N.: Motoare sincrone cu magneti permanenti si reluctant variabila,Editura Tehnica, Bucuresti, 1982.
[16] Măgureanu R., Vasile N.: Servomotoare fără perii tip sincron, Editura Tehnică, București, 1990.

[17] Vasiliu G., Suchar I., Serban G.: Micromotoare de current continuu cu comutatie statica, Editura Tehnica, Bucuresti, 1976.

[18] Tudorache T., Popescu M.: Optimal Design Solutions for Permanent Magnet Synchronous Machines, AECE Journal, Vol.11, Issue 4, Year 2011, ISSN: 1582-7445, e-ISSN: 1844-7600,pp.77-82.

[19] Tudorache T., Popescu M., Marin E.: Generatoare sincrone cu magneți permanenți pentru turbine eoliene de mică putere, Simpozionul de maşini electrice SME'10, 7-8 Oct. 2010.

[20] Vlad I., Campeanu A., Enache S., Enache Monica: Aspects regarding optimal design of high power squirrel cage asynchronous motors, OPTIM 2012, pp. $503-508$.

[21] Vlad I., Campeanu A., Enache S., Enache Monica: Aspects regarding design of squirrel cage asynchronous motors for mining excavators, Anals of the University of Craiova, Series Electrical Engineering, Year 36, No. 36, 2012, ISSN 1842-4805, pp. 57-62.

[22] Vlad I., Campeanu A., Campeanu T.: Considering the Influence of Upsetting and Saturation on Behaviour of Asynchronous Machines, SPEEDAM 2004, Proc. Vol.2, p.37-42.

[23] Vlad I., Campeanu A., Enache S.: Improvement of pre-determination precision of operation characteristics for asynchronous motor by considering magnetic saturation, SPEEDAM 2008, Ischia, pp. 614-619.

[24] Wang J., Xia Z., Howe D.: Three-phase modular permanent magnet brushless machine for torque boosting on a downsized ICE vehicle, IEEE Trans. On Vehicular Technology, vol. 54, no. 3, 2005, pp. 809-816.

[25] CEI 60034-2-1 Standard: Rotating electrical machines-Part 2-1. Standard methods for determining losses and efficiency from tests. 